\title{
Instrumentalización Correlacional para el Desarrollo del Pensamiento de Estudiantes de Preescolar y de Primaria desde la Formación del Espíritu Investigativo y de la Comprensión Textual
}

\section{Correlational Instrumentalization for the Development of the Thinking of Preschool and Primary Students from the Formation of the Investigative Spirit and Textual}

\author{
Aura A. Ramón ${ }^{1}$, Doris Vanegas ${ }^{2}$, Nataly Monroy $^{3}$ y Yenny C. Castellanos ${ }^{4}$
}

\section{○ \\ EDICIÓN: 进eIVTAC}

Recibido: 14/julio/2020

Aceptado: 6/agosto/2020

Publicado: 25/septiembre/2020

特 Colombia

${ }^{2}$ Colombia

${ }^{3}$ Colombia

${ }^{4}$ Colombia

\section{IIInstitución}

'Universidad de Pamplona

${ }^{2}$ Universidad de Pamplona

${ }^{3}$ Universidad de Pamplona

${ }^{4}$ Universidad de Pamplona

\section{Correo Eletrónico}

1auralexa@hotmail.com

²dvanegas@unipamplona.edu.co

3dvanegas@unipamplona.edu.co

${ }^{4}$ carolinacastellanos1@gmail.com

\section{(1)ORCID}

${ }^{1}$ https://orcid.org/0000-0003-1252-9983 ${ }^{2}$ https://orcid.org/0000-0003-1252-9983 3https://orcid.org/0000-0003-1252-9983 ${ }^{4}$ https://orcid.org/0000-0003-2076-2216

\section{Citar así: C4APA / IEEE}

Ramón, A., Vanegas, D., Monroy, N. \& Castellanos, Y. (2020). Instrumentalización Correlacional para el Desarrollo del Pensamiento de Estudiantes de Preescolar y de Primaria desde la Formación del Espíritu Investigativo y de la Comprensión Textual . Revista Tecnológica-Educativa Docentes 2.0, 9(2), 108-118.

A. Ramón, D. Vanegas, N. Monroy y Y Castellanos, "Instrumentalización Correlacional para el Desarrollo del Pensamiento de Estudiantes de Preescolar y de Primaria desde la Formación del Espíritu Investigativo y de la Comprensión Textual RTED, vol. 9, n. ${ }^{\circ}$ 2, pp. 108-118, sep. 2020.

\section{Resumen}

El desarrollo del pensamiento como formación de una competencia cognitiva en estudiantes de Preescolar a Primaria, en correlación con la formación de un espíritu investigativo y de comprensión textual, sin duda, aportan en la materialización de modelos pedagógicos como el constructivista o el sociocrítico. Este trabajo, por consiguiente, tuvo como objetivo generar una instrumentalización correlacional del pensamiento, la formación investigativa y la lectura textual en situaciones de aula o de semillero de investigación, como fortalecimiento al desarrollo curricular en mira a la formación integral. En este estudio, han sido vitales los aportes sobre el desarrollo del pensamiento; la formación del espíritu investigativo, observacional, experiencial; y, el desarrollo de una competencia textual. La metodología cualitativa hermenéutica asumida, corresponde al método heurísticosignificativo, texto lingüístico, semiótico e investigativo mixto. Como resultados, la instrumentalización en una matriz correlacional, con tres inventarios articulados (pensamiento-investigación-comprensión textual). Para la obtención de los resultados, fueron aplicados los métodos mencionados. Otro resultado investigativo, lo constituye el mentefacto base en el que ha sido presentada la aproximación teórica, metodológica, éticofilosófica y práctica de los objetos de estudio. La instrumentalización en este caso se realizó de forma integrada, coadyuvante, a diferencia del enfoque cognitivo como lo realiza la pedagogía conceptual. Este trabajo aporta al docente una herramienta útil para la inclusión de aprendizajes y actividades en el aula o fuera de ella, que lleven a una formación de calidad.

Palabras clave: Competencia cognitiva, competencia investigativa, competencia textual.

\section{Abstract}

The development of thought as formation of cognitive competence in preschool to primary students, in correlation with the formation of an investigative spirit and textual understanding, undoubtedly contribute to the materialization of pedagogical models such as constructivist or sociocritical. This work, therefore, had the objective of generating a correlational instrumentalization of thought, investigative training and textual reading in classroom or research hotbed situations, as a strengthening of curricular development with a view to comprehensive training. In this study, contributions on the development of thought have been vital; the formation of the investigative, observational, experiential spirit; and the development of a textual competence. The assumed hermeneutical qualitative methodology corresponds to the heuristic-significant, text linguistic, semiotic, and investigative mixed method. As results, the instrumentalization in a correlational matrix, with three articulated inventories (thought-research-textual understanding). To obtain results, the methods were applied. Another investigative result is the basic mindset in which the theoretical, methodological, ethical-philosophical, and practical approach of the objects of study has been presented. The instrumentalization in this case was carried out in an integrated, adjuvant way, unlike the cognitive approach as it is done by conceptual pedagogy. This work provides the teacher with a useful tool for the inclusion of learning and activities in or outside the classroom, leading to quality training.

Keywords: Cognitive competence, investigative competence, textual competence. 


\section{Introducción}

El presente estudio ha tenido como propósito contribuir en el desarrollo del pensamiento de los estudiantes de preescolar a primaria, principalmente, con base en el fortalecimiento del espíritu investigativo desde la comprensión textual de estos estudiantes, tanto en escenarios de aula como en actividades extraescolares. No obstante, en la visión del desarrollo del pensamiento ha sido abarcada secundaria.

Justificó este trabajo los grandes aportes teórico-metodológicos existentes que deben ser retomados para el mejoramiento educativo, como los de Feuerstein (1996), Vygostsky (1993), de Zubiría (1998), en cuanto al desarrollo del pensamiento; Comenio, con su Didáctica Magna en 1632 (1986), Montessori, con el Método de Pedagogía Científica en 1909 (2004), las escuelas municipales de Reggio Emilia como modelo de calidad en educación infantil (Berasluce, 2019), Halliday (2013), quien contextualiza una función heurística, y Stenhouse (1998), como propulsores del espíritu investigativo, observacional, experiencial; van Dijk (1980), van Dijk (2006), Solé (1992), Rincón (2004), López \& Vanegas (2005), López \& Vanegas (2007), Vanegas \& Ramón (2019), y las prospectivas del Ministerio de Educación Nacional en Colombia, en materia de comprensión textual hacia el desarrollo de una competencia textual.

Aportes tan relevantes que desafortunadamente aún no suelen impactar el trabajo de aula ni el de los deberes escolares o tareas en casa. Consecuentemente, los estudios previos abordados evidenciaron que se han realizado intervenciones para mejorar el desempeño cognitivo de los estudiantes, pero no suelen ser triangulados con competencias actitudinales ni procedimentales correlacionalmente. Al respecto, cabe resaltar los trabajos de Cedillo (2010), de Castro \& Herrera (2012), en los que muestra una necesidad de asumir teorías como la de Feuerstein hacia un camino de mejoramiento de las operaciones mentales. Herrero \& Martínez (2018) también evidenciaron que muchas veces los estudiantes no llegan a determinada evolución del pensamiento, no por falta de capacidad, sino por falta de mediación.

Por consiguiente, otro de los aspectos en los que puede contribuir este trabajo, radica en el fortalecimiento de una competencia pedagógica del del docente al poder contar con una gama de posibilidades para diversificar y optimizar su intervención. El hacer en el aula podrá conducir a la instrumentalización del pensamiento, cada vez más abastecido por la experiencia y por la mediación.

No es desconocido el desempeño lector por mejorar, en resultados de pruebas nacionales e internacionales. Los procesos de enseñanzaaprendizaje en torno a lectoescritura en el panorama internacional, presenta falencias a nivel mundial; es por ello, que para el año 2019, la prueba PISA mostró que "cerca del $20 \%$ de los estudiantes de los países de la OCDE, no obtienen una media en las competencias lectoras básicas. Esta proporción se ha mantenido estable desde 2009" (OCDE, 2019, p. 4).

El escenario no deja de ser distinto en el panorama nacional colombiano. Aspecto que está generando una brecha de desempeño académico que desplaza a nuestros territorios en materia de calidad. Es decir, que, a pesar de contar con estudiantes con altas posibilidades de desarrollar su competencia cognitiva, existe amenaza en creer que, por pertenecer a determinados grupos sociales, no puede haber aprendizajes de calidad.

Esta situación ha tenido sus raíces en países como Colombia, en condiciones de desigualdad socioeconómica, en particularidades históricoculturales, políticas, ambientales de sus regiones, en brechas educativas comunicativas, tecnológicas, humanísticas, científicas e investigativas que acontecen. No obstante, la práctica pedagógica enfrenta el gran desafío de pasar de rutina pasiva a interacción creativa, crítica, estimulante, donde los estudiantes aprendan a develar, a analizar, a inventar, a producir, y a solucionar problemas, entre otras capacidades cognitivas (Guillen, 2020, p. 2); de hecho, los nuevos modelos educativos se basan en que las personas conocen, comprenden el mundo a partir de sus emociones, significados, vivencias y su cultura (Zeballos, 2020).

Actualmente, según modalidad formativa, la Pedagogía de Educación Virtual (MEN, 2019), implica nuevos retos en educación en cuanto a quién enseña/aprende, quién aprende/enseña, para qué enseña/aprende, qué enseña/aprende, en qué secuencia enseña/aprende, cómo enseña/aprende, con qué recursos enseña/aprende y cómo evalúa el enseñar/aprender.

Se trata entonces de contribuir en una minimización de las diferencias, para que así sea 
una educación privada o una educación pública o una rural, presencial o virtual, pueda formar un espíritu investigativo que permita conocer el contexto sociocultural e histórico del momento que vivimos, una formación humanística que permita entender el mundo, ser útil a una sociedad y a conservar el medio ambiente. Formación de un ser con otros en armonía, que dé soluciones para mejorar la calidad de vida y evidencie saber vivir en comunidad (Vanegas, Ramón \& Lizarazo, 2017).

Por consiguiente, invitamos a entender y a valorar el aporte que con gran dedicación ha sido materializado en este escrito. Encontrarán una concepción tridimensional sistémico-compleja del desarrollo del pensamiento, con su análisis desde un mentefacto. Al final, una matriz correlacional que articula el desarrollo del pensamiento con insumos para formación investigativa y comprensión textual.

\section{Metodología}

El enfoque investigativo cualitativo hermenéutico (Martínez, 2002) ha guiado el estudio con apoyo del método heurístico-significativo (Vanegas \& López, 2015), el texto-linguiístico, el semiótico y el investigativo mixto. Han sido imbricados estos métodos debido al comportamiento complejo del objeto de estudio abordado. En el mentefacto desarrollado ha sido evidenciado el modo como cada método ha aportado al estudio. La población considerada ha sido delimitada en educación preescolar a primaria, por importancia, gran relación y repercusión del tránsito de un nivel a otro; sin embargo, ha sido presentada una visión completa hasta secundaria.

La población que participó en el estudio correspondió a labor de un semillero de investigación en primaria y a estudio de casos de estudiantes de preescolar. No obstante, el estudio está orientado hacia una correlación de pensamientos, materiales, estrategias, actividades y conocimientos puntuales en una matriz; siendo conscientes que cuando un medio o instrumento irrumpe en una sociedad, la redefine profundamente (Gutiérrez-Cortés, Islas-Carmona \& Arribas-Urrutia, 2019), no se pretende medir efectividad de una propuesta sino únicamente contextualizar dicho instrumento pedagógico didáctico, dejándolo disponible para otros
Por consiguiente, el resultado relevante consiste en el haber generado una matriz correlacional del desarrollo del pensamiento respecto a una formación investigativa y a una comprensión textual con las competencias que le competen a cada uno. Como aporte también puede apreciarse el mentefacto generado sobre desarrollo del pensamiento, en consideración de una competencia cognitiva.

Según lo planteado hasta el momento, precisa ver un objeto de estudio de carácter tridimensional sistémico complejo. En la siguiente figura pueden observarse las interacciones con complementariedad de los aportes teórico-metodológicos, filosóficoéticos y prácticos (ver figura 1). Sin embargo, es importante resaltar el espíritu humanístico que inspiró este estudio, una formación integral desde la formación del espíritu investigativo que se apoya en los estudios realizados por expertos en el área del lenguaje, en pedagogía, en sociocultura, en discurso y en interdisciplinariedad.

\section{Figura 1}

\section{Concepción tridimensional sistémico-compleja de} una formación integral.

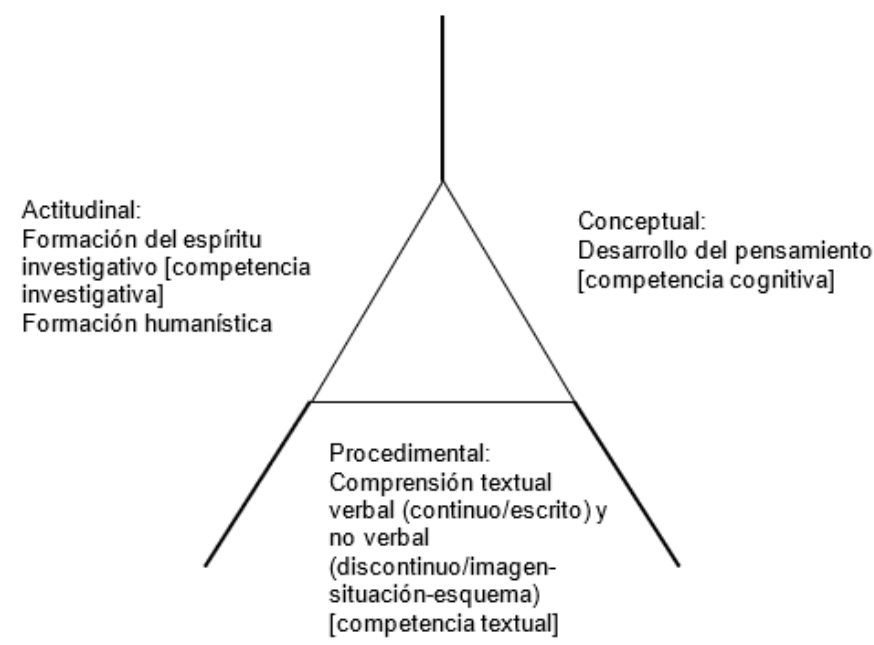

Nota. Mirada sistémico-compleja de una formación integral que permite articular el saber, el ser y el hacer. Figura de elaboración propia.

A continuación, ha sido resumida en una herramienta cognitiva de mentefacto (ver figura 2) una concepción en constructo teórico de los objetos de estudio abordados, así como una vinculación del sustento teórico, filosófico y metodológico. educadores. 
Instrumentalización Correlacional para el Desarrollo del Pensamiento de Estudiantes de Preescolar y de Primaria desde la Formación del Espíritu Investigativo y de la Comprensión Textual.
CONGRESO INTERNACIONAL VIRTUAL SOBRE LAS TECNOLOGÍAS DEL APRENDIZAJE Y DEL CONOCIMIENTO
Figura 2

\begin{tabular}{|c|c|c|c|}
\hline \multicolumn{4}{|c|}{ tegral } \\
\hline \multicolumn{4}{|c|}{$\begin{array}{l}\text { Desarrollo del pensamiento en Preescolar, Primaria y Secundaria } \\
\text { (competencia cognitiva) } \neq \text { Información } \\
\text { 8. Estudio correlacional }\end{array}$} \\
\hline $\begin{array}{l}\text { Subcategorías } \\
\text { culturales } \\
\text { seleccionadas: }\end{array}$ & $\begin{array}{l}\text { 8.1 Reconocimiento, } \\
\text { uso de: }\end{array}$ & $\begin{array}{c}\begin{array}{c}\text { 8.2 Reconocimiento } \\
\text { de formación } \\
\text { investigativa, competencia } \\
\text { investigativa, uso de: }\end{array} \\
\end{array}$ & $\begin{array}{c}8.3 \text { Reconocimiento de } \\
\text { comprensión textual, } \\
\text { competencia textual, } \\
\text { uso de: }\end{array}$ \\
\hline \multirow{6}{*}{$\begin{array}{l}\text { 1. Definición } \\
\text { 4. Tipos de pensamiento } \\
\text { (Zubiria) } \\
\text { 5. instrumentos del } \\
\text { pensamiento, } \\
\text { estructuración cognitiva } \\
\text { 6. Niveles de desarrollo } \\
\text { (Piaget, Iafrancesco) } \\
\text { 7. Estrategias para el } \\
\text { desarrollo del } \\
\text { pensamiento (Flórez) } \\
\text {-Juego } \\
\text {-Pregunta } \\
\text { Investigación } \\
\text { 8. Estudio correlacional }\end{array}$} & $\begin{array}{l}\text { 8.1.1 Procesos de } \\
\text { pensamiento } \\
\text { (Iafrancesco) }\end{array}$ & $\begin{array}{l}8.2 .1 \text { Función heuristica } \\
\text { (Halliday) }\end{array}$ & $\begin{array}{l}\text { 8.3.1 Conocimiento del } \\
\text { texto (López \& Vanegas) }\end{array}$ \\
\hline & $\begin{array}{l}8.1 .2 \text { Operaciones } \\
\text { mentales }\end{array}$ & $\begin{array}{l}\text { 8.2.2 Modelo natural } \\
\text { (Comenio) }\end{array}$ & $\begin{array}{l}\text { 8.3.2 Competencia } \\
\text { textual (López \& } \\
\text { Vanegas) }\end{array}$ \\
\hline & $\begin{array}{l}81.3 \text { Funciones } \\
\text { cognitivas } \\
\text { [Feuerstein] }\end{array}$ & $\begin{array}{l}\text { 8.2.3 Aula investigativa } \\
\text { (Montessori) (Experiencia } \\
\text { Reggio Emilia) }\end{array}$ & $\begin{array}{l}\text { 8.3.3 Categorias de } \\
\text { análisis de lectura } \\
\text { (MEN) }\end{array}$ \\
\hline & $\begin{array}{l}\text { 8.1.4 Actos mentales } \\
\text { de lo simple a lo } \\
\text { complejo (Vanegas \& } \\
\text { Ramón) } \\
\text { Instrumentalización } \\
\text { [abstraer, entender, } \\
\text { relacionar, } \\
\text { correlacionar, } \\
\text { analizar, resumir, } \\
\text { contextualizar, } \\
\text { interpretar inferir, } \\
\text { generalizar, } \\
\text { concluir...] (Vanegas } \\
\text { \& Ramón) }\end{array}$ & $\begin{array}{l}\text { 8.2.4 Docente investigador } \\
\text { (Stenhouse) }\end{array}$ & 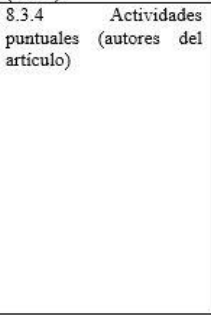 \\
\hline & $\begin{array}{l}8.1 .5 \\
\text { Representaciones } \\
\text { cognitivas: mapas } \\
\text { conceptuales, } \\
\text { constructos, } \\
\text { mentefactos, } \\
\text { diagramas de flujo } \\
\text { (Vanegas \& Ramón) }\end{array}$ & $\begin{array}{l}8.2 .5 \text { Competencia } \\
\text { investigativa (autores del } \\
\text { articulo) }\end{array}$ & \\
\hline & \begin{tabular}{|l}
8.1 .6 Actividades que \\
favorecen ren \\
desarrollo $r$ del \\
pensamiento (autoras \\
del artículo)
\end{tabular} & $\begin{array}{l}\text { 8.2.6 Actividades puntuales } \\
\text { (autores del articulo) }\end{array}$ & \\
\hline
\end{tabular}

Nota. La instrumentalización a través de herramientas cognitivas como el mentefacto, ha sido propuesta por la Pedagogía Conceptual. Figura de elaboración propia.

\section{Desarrollo de Subcategorías Seleccionadas}

5. Definición de Desarrollo del Pensamiento. Según Piaget (1976), el desarrollo intelectual tiene que entenderse como una evolución a través de estadios de pensamiento cualitativamente diferentes. El pensamiento es diferente en cada edad; no es una distinción de "cantidad" (mayor o menor capacidad para pensar, mayor o menor habilidad cognitiva), sino de "cualidad" (se piensa de forma distinta a distintas edades); según Vygotsky (1993), el desarrollo cognitivo tiene lugar mediante la interacción del niño con el adulto o con niños mayores, con el punto medio de la zona de desarrollo procedimental, en áreas en que el niño no puede resolver solo el problema. Los niños nacen con ciertas habilidades básicas para facilitar su adaptación y comprensión, entre estas figuran: La sensación, la atención, la memoria y la percepción; según Feuerstein (1996), cualquier individuo es susceptible de mejorar su capacidad intelectual, aprender y aprender a aprender si se involucra en experiencias de aprendizaje mediado. No hay límite posible en el desarrollo intelectual si cuenta con una buena mediación, independientemente de las carencias del sujeto; según Zubiría (1998), el pensamiento tiene tres grandes componentes: los instrumentos del conocimiento, los procesos de pensamiento y la metacognición.

1. Formación humanística integral (Comenio, Morin, Zubiría). Desde Comenio, se da un lugar importante al niño en formación, desde un modelo que podríamos llamar "natural". Morin (1994), desde su mirada compleja, ve al sujeto en formación desde múltiples dimensiones. Zubiría (1998), desde el planteamiento de una pedagogía conceptual, orientada hacia la formación de un ser humano útil a la sociedad cuyo móvil es el amor por lo que hace y por la humanidad de que forma parte.

2. Información. Según Mújica, presidente uruguayo, citado por Zubiría (2014, p. 7), "los depósitos de conocimiento no van a estar más dentro de nuestras cabezas, sino ahí afuera, disponibles para buscarlos por Internet. Ahí va a estar toda la información, todos los datos, todo lo que ya sabe. En otras palabras, van a estar todas las respuestas. Lo que no van a estar son todas las preguntas. En la capacidad de interrogarse va a estar la cosa. En la capacidad de formular preguntas fecundas, que disparen nuevos esfuerzos de investigación y aprendizaje".

3. Tipos de pensamiento (Zubiría). Según Zubiría (1998), en el desarrollo del pensamiento se consideran diversos tipos de pensamiento: el nocional (nociones como nombres/sustantivos, acciones/verbos...), el proposicional (relaciona nociones), el conceptual (relaciona proposiciones), y el formal (relaciona conceptos, caracterizado por lo categorial, hipotético-deductivo, analógico, divergente...).

4. Instrumentos del pensamiento, estructuración cognitiva. Según Zubiría (2014) para pensar requerimos instrumentos del conocimiento y de procesos de pensamiento. A través de la mediación de calidad, los instrumentos se van tejiendo, complejizando e integrando, partiendo de 
través de la mediación de calidad, los instrumentos se van tejiendo, complejizando e integrando, partiendo de nociones espaciales, temporales y transdisciplinarias, hasta llegar a estructuras argumentativas ramificadas, que usan lógicas modales y niveles de argumentatividad, las cuales integran $\mathrm{y}$ articulan otros instrumentos como las proposiciones, los conceptos, los razonamientos inductivos y deductivos. Para Piaget, las nuevas experiencias obligan a adaptar los esquemas de conocimiento previos: tal adaptación, que pueden dividirse en los subprocesos de asimilación de informaciones y acomodación de estas a los esquemas o estructuras cognitivas previas, desemboca en el aprendizaje. Por consiguiente, organización o proceso de categorización y sistematización de los conocimientos (de hecho, esta reorganización) es constante.

6. Niveles de desarrollo (Piaget, Iafrancesco). Para Piaget (1976): Etapa sensorio - motora o sensiomotriz (0 a 2 años: oraciones simples, juegos de experimentación, interacciones con objetos, personas y animales cercanos, egocentrismo), etapa preoperacional ( 2 a 7 años: capacidad de ponerse en el lugar de los demás, actuar y jugar siguiendo roles ficticios, utilizar objetos de carácter simbólico, pensamiento mágico basado en asociaciones simples, un poco menos egocentrista), etapa de operaciones concretas ( 7 a 12 años: lógica para llegar a conclusiones válidas, siempre y cuando las premisas desde las que se parte tengan que ver con situaciones concretas y no abstractas. Además, los sistemas de categorías para clasificar aspectos de realidad pueden ser notablemente más complejos en esta etapa) y etapa de operaciones formales (desde los 12 años hasta vida adulta: capacidad para utilizar lógica para llegar a conclusiones abstractas que no están ligadas a casos concretos que han sido experimentados de primera mano, analizan, manipulan esquemas de pensamiento, usan el razonamiento hipotético deductivo). Para Iafrancesco (2013): Para aprender a pensar científicamente, es necesario desarrollar el potencial en: 1 . Mecanización-memorización. 2. Concreción- interpretación.

3.

Configuraciónestructuración. $4 . \quad$ Abstracciónargumentación. 5. Relaciones lógicashipótesis-deducción. 6. Formalizaciónproposición.

7. Estrategias para el desarrollo del pensamiento. Según Flórez (2013), Toda estrategia de enseñanza implica una secuencia ordenada de acciones para conseguir alguna meta de formación; en ese sentido trasciende lo técnico y lo procedimental. Las estrategias para desarrollar el pensamiento y garantizar una formación del estudiante son: (a)Juego. El juego, en una función del descubrimiento, permite que los niños vean en sí mismos un explorador, para que descubran secretos, sean investigadores o creadores. El juego es impredecible, divertido y apasionante, no se sabe cuál va a ser el final. Es flexible y adaptable a los cambios de dirección, dispone de ciertas reglas que prepara al niño para la vida adulta. El juego capta la atención, es motivante porque en cualquier momento diversas posibilidades pueden ocurrir, es cooperativo y es un camino efectivo de socialización. (b) Pregunta. La pregunta como estrategia de enseñanza es la que genera en los estudiantes reflexión crítica, constructiva y autónoma sobre un área de conocimiento: esta estrategia le pertenece principalmente a la pedagogía constructivista-Investigación. "Uno no busca ni investiga lo que no desea saber; y el que cree que todo lo sabe no puede preguntarse nada, pues toda pregunta es una cierta porción de duda. La pregunta es una apertura y un camino a alguna respuesta que no se sabe. Por eso se dice que la pregunta es el camino del saber, porque ella tiene un sentido, una orientación para la búsqueda". (Flórez, 2013, p. 23).

8. Estudio correlacional. Estima diversos aspectos que pueden ser integrados para favorecer el desarrollo del pensamiento. En este caso, desglosa lo concerniente a categorías del desarrollo del pensamiento, posibles intervenciones en una formación investigativa con algunas mediaciones que pueden tener lugar en el afianzamiento lector. 


\section{Resultados}

A continuación, presentamos una matriz de correlación para el desarrollo del pensamiento en Preescolar y Primaria desde estrategias para formar el espíritu investigativo con estrategias de comprensión textual (ver Tabla 1). Los datos utilizados para esta conformación de inventarios provienen de la revisión documental y algunos de ellos han sido llevados a aplicación; por consiguiente, el origen es diverso pero pedagógica y didácticamente viables en ámbitos educativos, formativos de carácter constructivista o sociocrítico. Razón por la cual, han sido aclarados los escenarios de aplicación a través de las situaciones de enseñanza y de aprendizaje.

\section{Tabla 1}

Matriz de correlación para el desarrollo del pensamiento.

Matriz de correlación para el desarrollo del pensamiento en Preescolar, Primaria y Secundaria desde la formación del espíritu investigativo y la comprensión textual.

\section{Situaciones de enseñanza y de aprendizaje}

Ver el mundo como una piscina de significados, donde coexisten diversos códigos: letras, colores, formas, números, señales, iconos...

Uso de textos continuos y discontinuos.

Participación en actividades grupales como rondas, juegos. Imitación de animales.

Comprensión y aprendizaje de canciones, poemas, juegos de palabras.

En educación inicial, en textos breves, encerrar letras, sílabas, palabras que empiezan por tal letra...

En primaria: palabras de una sílaba, de dos, de tres..., sustantivos, adjetivos, verbos, adverbios, conjunciones, disyunciones, determinantes, oraciones simples, oraciones compuestas.

Percepción de la intencionalidad del hablante por el manejo que él hace de la intensidad de la voz, la entonación y los gestos.

\section{Desarrollo del pensamiento- competencia cognitiva (conceptual)}

Atención, escucha percepción, observación, participación, colaboración

\author{
Afianzamiento comprensión textual-
competencia textual \\ Afianzamiento comprensión textual-
competencia textual \\ (procedimental)
} (actitudinal) Observación cada vez con más atención
de láminas, películas, títeres.

Buscar, ubicar objetos.

Explorar más atentamente su realidad.

Expresar emociones y vivencias a través del lenguaje gestual y verbal.

Leer figuras, imágenes y actitudes.

Observación con interés de imágenes y fotografías.

Ir construyendo la noción de: línea, círculo, arriba y abajo, grueso y delgado, grande y pequeño, izquierda y derecha, día y noche, redondo, cuadrado, y triangular, sobre y debajo, gordo y flaco, grande y pequeño, largo y corto, dentro y fuera, cerca y lejos, muchos y pocos, primero y último, pesado y liviano...

Relacionar objetos entre sí.

Practicar el collage.

Agrupar objetos según su especie: zapatos con zapatos, medias con medias..

Orientarse espacialmente.

Encontrar el camino correcto.

Relacionar conceptos nuevos con otros ya conocidos.

Establecer relaciones con el medio ambiente y con las actividades que desarrollan las personas de su entorno.

Ubicar las voces, los lugares, el tiempo, las causas o razones, las intenciones, los hallazgos, los problemas, las soluciones, las motivaciones, los gustos, las ventajas, las desventajas...

Salidas de campo, laboratorios.

Diseñar diarios de campo para registrar observaciones sobre objetos, animales, sucesos, situaciones... Captar información.
Escuchar canciones, cuentos y poemas. Disfrutar con lecturas vivaces de cuentos y poesías.

Disfrutar de la música, los títeres, las películas, las canciones, los cuentos y los poemas para desarrollar la sensibilidad y la imaginación.

Perfeccionar la pronunciación de las palabras e incorporar otras nuevas.

Imaginar y expresar posible continuación de un cuento, película.

Reconocer el texto como forma de acercarse al saber y a la recreación.

Fortalecer la percepción visual, auditiva, táctil, olfativa y su orientación espacial y temporal a través del conocimiento del texto (posiciones; distribución de la información en el texto; letras: consonantes y vocales, mayúsculas y minúsculas, script y cursiva; el renglón; espacios; imágenes; márgenes; partes...

Leer e imitar las acciones que tiene lugar en un texto.

Leer proposiciones cotidianas, redescubriendo la magia del lenguaje y la función de este en la vida de los seres humanos.

En un texto, subrayar en colores diferentes según categorías: narrador(violeta), protagonista o personaje principal (rojo), otros personajes que ayudan al protagonista (rosado), otros personajes que no ayudan al protagonista o antagónicos (negro) espacio(verde), tiempo(azul), causas(amarillo), intención(naranja). 


\begin{abstract}
Atender y escuchar
mientras se lee un texto.

Para aprender las vocales, una en una, empezar por dibujarla en el piso, caminar sobre ella, empezando a transitarla desde donde debe empezar a hacer el trazo; luego llevar a una hoja en tamaño grande, bordear con diversos materiales, se guía desde dónde empieza el trazo, poco a poco ir descubriendo en otros lugares...
\end{abstract}

Pintar, colorear, usar diversos materiales ayudan a la interiorización.

Encerrar, subrayar, resaltar, transcribir, repetir palabras, trabalenguas, palabras ilustradas, caligrafía...

Diagramar, dibujar, imitar lo que sucede en un texto o con un personaje en

particular.

Dar cuenta de...

Glosarios, diccionarios.

Acercamiento a temas de interés.

Guías de trabajo

Hallar diferencias entre

dibujos.

Sopa de letras. Deletreo.

Palabras escondidas.

Antónimos.

Impostación de la voz según palabras. Cuantitativo vs cualitativo.

Ortografía.
Representación entendimiento y diferenciación

\section{Abstracción,} interiorización identificación, comprensión, documentación, interacción, diálogo
Imaginar, adivinar, sentir, jugar: qué pasaría si..., describir personajes: cómo se visten, cómo son física, espiritualmente, qué hacen...

Captar características de objetos concretos, abstractos.

Ideogramas.

Veo. veo...

Explorar sistemáticamente para lograr identificar...

Ir de lo tangible a lo intangible.

Expresar, comentar, relatar, pintar con palabras vivencias, situaciones. Interactuar en diálogos cotidianos.

Identifica los datos que conforman una referencia bibliográfica.

Consultar en Biblioteca, en internet, en diversas fuentes.

Interpretar signos de comportamiento, cortesía, protocolo.

Participar en las distintas técnicas grupales como mesa redonda, debates...

Hacer uso de la historieta para representar lo que sucede en un texto. Representación de información en gráficos, tablas, tortas, figuras, fichas técnicas...

Usar símbolos.

La lluvia de ideas sobre un tema.

La anémona (un centro/tema con brazos/ características).

Realización de consultas o micro monografías sobre indagación de objetos de estudio.

Situar palabras según el contexto, estudiar semejanzas, diferencias entre objetos, hechos, según características. Leer proposiciones cotidianas y científicas, diferenciándolas entre sí.

Unir, agrupar según

criterio.

Juego de stop (en casillas: nombre, ciudad, animal, fruta...quien primero termina grita stop, van sumando puntos), descubrir analogías (Ej.: padre-hijo como madre-hija).

Usar rejillas con listas.

Sinónimos. Inventarios. contextualización situación geográfica, histórica,

filosófica, cultural.

Confrontar ideas, pensamientos.

Plantear ejemplos. Simular personajes, situaciones.

Propiciar la inferencia, la suposición, la presuposición, la búsqueda de lo implícito.
Relación y contextualización, interpretación, pensamiento inferencial
Concurso alcance una estrella (en cada una hay una pregunta sobre el tema que se está estudiando),

Evocación de palabras (decimos sol y la palabra brilla).

Concéntrese (en diversos sitios cubiertos hay parejas, tratar de descubrirlas).

Línea de tiempo. Localización en mapamundi. Reconocimiento de ciencias y de disciplinas o campos de estudio. Reconocimiento de pensadores y de diversas culturas.

Relacionar interdisciplinarmente, plantear sistemas complejos.

Orientarse espacial, temporalmente.
Identificar los enunciados en el texto descubrir las proposiciones que forman parte de él.

En textos narrativos, reproducir en mente lo que lee, escucha (descripciones, acciones que viven y sienten).

Identificar verbos conjugados, sustantivos, adjetivos, adverbios, palabras clave...

Recrear verbalmente situaciones y vivencias con sus propias palabras, haciendo uso de nociones espacio temporales, personajes, acciones, calificativos...

Desarrollar diferentes niveles de comprensión del texto, indagando, cuestionando.

Manejar diferentes tipos de lectura.

Percibir claramente en los textos intencionalidad del autor.

Aplicar técnicas de lectura rápida.

Representar situaciones, momentos, escenas, personajes...pueden darse a conocer de otras formas.

Realización de consultas sobre biografías de autores, obras literarias.

Elaboración de fichas de lectura (bibliográfica, textual, resumen, paráfrasis, comentario).

Plantear binomio fantástico (ej:

armario/perro).

Aprehender conceptos, vocabulario.

Orientarse espacial, temporalmente en los textos.

Hallar relaciones entre sucesos presentes, pasados, futuros.

Situar el texto en el contexto sociohistóricocultural.

Reconocer el modo como funciona el contenido de un texto.

Realizar inferencias estableciendo relaciones, asociaciones entre los significados llevándolo a la lectura crítica. 


\begin{tabular}{lr}
\hline Dialogar texto, glosar. Precisar \\
categorías culturales, categorías \\
comunicativas, categorías \\
gramaticales, $\quad$ categorías
\end{tabular}
textuales..

Árbol de problemas. Indagar heurísticamente,

Jeroglíficos, acertijos. Análisis de cuentos, relatos, poemas, obras de teatro.

Precisión de ideas principales, secundarias, conclusiones.

Uso de signos de puntuación.

Reconocimiento de métodos y su aplicación.

Paralelo: unir palabras o frases. Completar. Seleccionar.

Palabras crecientes. Palabras decrecientes. Crucigramas. Sinónimos. Transcripciones. Paráfrasis. Acentuación.

Comparar textos.

Organizar objetos por tamaño, por color, por material, por forma, por sonido...

Ordenar...

Lista de palabras según Categorización, criterios (por orden alfabético, clasificación por categorías gramaticales...).
Desarrollar protocolos para resolver situaciones.

Elaboración de trabajos escritos sobre un tema, con nomenclador, con las normas básicas de citación del autor-es. Desarrollar mapas conceptuales, cuadros, sinópticos, mentefactos sobre temas específicos.

Utilizar árbol de problemas para analizar situaciones problema.

Realización de inventarios.

Descomponer un todo en sus elementos constitutivos.

Redactar adecuadamente preguntas para entrevistas, escritos para el periódico estudiantil.

Comparar, contrastar situaciones, textos. Elaborar cuadros comparativos, paralelos, tablas, matriz con diversos Comparación y aspectos que se estudian. contrastación Ejemplificar.

Categorizar a pesar de algunas variaciones (ej: mesa a pesar de haber redondas, cuadradas, de una, dos, tres, cuatro patas...).

Asumir criterios naturales, artificiales para categorizar.

Explorar categorías culturales de los objetos de estudio como definición, características, partes, elementos, funciones, origen, evolución.

Seleccionar cuidadosa y rigurosamente datos para llegar a la respuesta correcta. Selección de información relevante.

\begin{tabular}{lll}
\hline $\begin{array}{l}\text { Hacer rondas. } \\
\text { canciones, }\end{array}$ & $\begin{array}{l}\text { Aprender } \\
\text { Refranes. }\end{array}$ & $\begin{array}{l}\text { Concatenación, } \\
\text { causa-efecto, } \\
\text { Rompecabezas. }\end{array}$ \\
El teléfono rotoma- \\
Acrósticos. & & solución, \\
Describir. & & pensamiento \\
hipotético
\end{tabular}

Narrar.

Exponer.

Elaborar

maquetas.

Dramatizar.

Hacer dinámicas. Ambientar

un lugar. Secuenciar u

organizar secuencias,

conceptos, procesos.

Plantear situaciones problema.
Ordena palabras en frases hasta dar sentido, dibujar situaciones, acciones o películas, descubrir, construir, usar redes semánticas, llevar apuntes, desarrollar talleres

Organizar situaciones según corresponda a causa o a efecto.

Imaginar hipotéticamente. Plantear ideales.

Plantear objetivos. Elaborar matriz DOFA. Planificar, establecer metas específicas.

Con diagramas de flujo puede graficar el modo como de un problema llega a una solución.

Planteamiento de problemas.

Organización de datos o de información, operación o procedimiento, resultado.

Diagramas de flujo para saber de dónde empezar hasta dónde llegar en la solución de un problema,

en estudiantes mayores el uso de la v heurística ayuda a guiarse.

Usar información previamente almacenada. Percepción, definición de un problema. Delimitación de un problema.

Usar diferentes lupas o enfoques para procesar información.

Pensar operativamente.
Descubrir el sujeto y el predicado textuales en proposiciones, enunciados, párrafos, composiciones. Percibir el manejo temporal en el texto (presente, pasado y futuro).

Desarrollar protocolos para el acercamiento, comentario de textos: narrador/enunciador, focalizador/observador, perspectiva/ideología,

prospectiva/intención...

Desarrollar mapas conceptuales, cuadros sinópticos sobre obras específicas.

Discutir, argumentar, confrontar textos literarios teniendo en cuenta sus opiniones propias y las de los demás para llegar a una conclusión.

Puntualizar las características de las diferentes escuelas literarias, de sus autores más representativos.

Jerarquizar ideas.

Valerse de la lectura para fortalecer su pensamiento divergente, categorial.

Comparar las características de las distintas corrientes, momentos, obras, autores con base en categorías como contexto sociocultural, representantes, obras representativas, técnicas literarias, tratamiento de lo cotidiano, de lo social.. Clasificar los conocimientos presentes en el texto según sean de carácter científico, filosófico, religioso, cotidiano...

Concatenar acciones, características, ideas, causas, consecuencias. Aprender poemas e interpretarlos frente a los compañeros.

Leer oralmente.

Leer mentalmente.

Citar.

Referenciar.

Parafrasear.

Describir.

Narrar.

Elaboración de álbum, dossier, portafolio, archivo, carpeta.

Ubicar problemas, soluciones en los textos que leen y en el contexto.

Organizar planes textuales previos a la escritura a través de la elaboración de composiciones escritas. 


Organizar
acontecimientos o
situaciones de lo simple a
lo complejo. Seguir
procedimientos tipo taller
o tipo laboratorio hasta
obtener lo que se quiere.
Solución de problemas.
Solución de evaluaciones.
Desarrollar conducta
sumativa.

Inducción-

deducción:

Método I-D:

1.Observación de los hechos particulares (diagnóstico).

2.Formulación del problema para resolver (pregunta problema) 3.Planteamiento de hipótesis o posibles explicaciones. 4.Recolección de datos (cuáles y con qué instrumentos).

5.Análisis de

datos.

6.Resultados, discusión.

7.Conclusiones generales.

Pensamiento de lo particular a lo general, pensamiento matemático.

Textos mudos a los que se les debe asignar título.

Organizar situaciones particulares hasta llegar a la generalización (Ej: se empiezan a presentar casos sobre determinada enfermedad desconocida con $\mathrm{x}$ síntomas, llega el momento en que un científico articula los casos presentados hasta descubrir que se trata de una enfermedad nueva y le da un nombre, es decir la generaliza, cuando llega un nuevo caso ya se deduce según los síntomas que es la enfermedad $x$, se sigue su tratamiento).

Presentar resultados. Presentar conclusiones.

Enclusiones. número de elementos.

Escribir los números que faltan en la secuencia.

Dibujar elementos en relación con un número determinado.

Comparar pequeñas colecciones de objetos, estableciendo relaciones tales como "hay más que", "hay menos que", "hay tantos como" Desarrollar conducta sumativa (cuántas características, cuántas partes, cuántos elementos...).

Generar espacios de reflexión que permita jugar con la información, suponer, cuestionar, criticar, asumir roles, dar razones...

Justificar (según necesidades, brechas, oportunidades, posibles impactos...). Plantear proyectos de aula, proyectos pedagógicoproductivos.

Organizar mesas redondas, debates, foros, panel, sustentaciones... Uso de conceptos y de teorías, plantear constructos teóricos.

Explicar con base en preguntas.

Simular virtualmente.
Situarse críticamente en la realidad, en el contexto.

Generar preguntas. Cuestionarse qué piensa sobre esto o aquello, qué haría si...

Pensamiento

crítico,

pensamiento

divergente

argumentación,

proposición,

concertación,

valoración,

entronización,

corresponsabilidad

Asumir el rol de personas, situarse en la realidad de $\mathrm{x}$ persona.

Expresar ideas propias. Realizar revisión bibliográfica sobre un tema.

Realizar monografía sobre un tema. Plantear artículos de opinión/investigación,

aplicación/modelos. Realización de estudios propios.

Plantear proyectos de investigación de semillero.

Realizar documentales, reportajes.

Realizar autobiografía. Publicar resultados, trabajos.

Transformar mentalmente.

Evidenciar lo que se sabe, lo que se aprende, lo que se hace...

Reflexionar sobre lo que se piensa y se hace. Realizar metacognición.
Organizar una historia

cronológicamente (desde donde empezaron las acciones, cómo fueron sucediendo hasta su desencadenamiento).

Escribir exposición.

Escribir crónica.

Reconocer el tipo de texto que lee (cuento, poema, leyenda...),

Reconocer el tema general de que trata el texto.

Descubrir la intención del autor del texto.

Reconocer el protagonista de una historia.

Reconocer el motivo que desató la historia en un cuento o en una leyenda. Reconocer la forma de pensamiento de $\mathrm{x}$ personaje real o ficticio (cuál era su imaginario...).

Desarrollar conducta sumativa (cuántos personajes, cuánto tiempo, cuántos capítulos...).

Situarse en la realidad o en la ficción, asumir el rol de diferentes personajes. Plantear preguntas sobre lo que lee. Elaboración de afiches, carteleras, periódicos murales.

Uso de nuevas tecnologías. Participación en feria escolar, organización de stand temático. Participación en concursos.

Asumir un punto de vista, dar razones del porqué asume dicha posición. Escribir ensayo.

Escribir cuento, escribir poema, escribir guion. Aplicación de principios comunicativos (cortesía/pertinencia, cooperación/máximas de cantidadcalidad- modalidad, relevancia/ significación.

Innovar/crear.

\footnotetext{
Nota. Los planteamientos de Zubiría (1998) y de Piaget (1976) sobre el desarrollo del pensamiento e instrumentalización del conocimiento desde lo más simple a lo más complejo, han sido una base para la consideración de esta matriz correlacional que considera aspectos actitudinales y procedimentales, elaboración propia.
} 


\section{Conclusiones}

Los sustentos teóricos han sido pertinentes, suficientes, esclarecedores del desarrollo del pensamiento, de una formación investigativa y de una comprensión textual. El procedimiento seguido respecto al uso de los métodos requeridos ha sido adecuado para el logro que se buscaba, la consolidación de una matriz correlacional.

Los procesos cognitivos que tienen lugar en el desarrollo del pensamiento fueron agrupados por afinidad en diez categorías graduales para facilitar su captación y el entendimiento de su complejidad:

1. Atención, escucha, percepción, observación, participación, colaboración.

2. Abstracción, interiorización, identificación, comprensión, interacción, diálogo.

3. Representación, entendimiento, diferenciación.

4. Relación, contextualización, interpretación, pensamiento inferencial.

5. Análisis-síntesis.

6. Comparación, contrastación.

7. Categorización, clasificación.

8. Concatenación, causa a efecto, problema a solución, pensamiento hipotético

9. Inducción a deducción, Pensamiento particular a general, pensamiento matemático.

10. Pensamiento crítico, pensamiento divergente argumentación, proposición, concertación, valoración, entronización, corresponsabilidad.

En estos procesos fueron incluidos algunos procesos volitivos de carácter actitudinal porque muchos de ellos hacen del ser humano, un ser más consciente de su saber, de su sentir, de su hacer como ser integral. Formar un espíritu investigativo en relación con la lectura invita a abordar diversidad de textos, de situaciones, a propiciar un pensamiento crítico, consciente, que aprenda desde las experiencias más sencillas a las más complejas. El trabajo Preescolar a Primaria dará las bases para un pensamiento más complejo en secundaria; una instrumentalización del conocimiento, gradual, en continuo enriquecimiento.

Pretendió este trabajo dar una idea de cómo generar situaciones en el aula o en el hogar para desarrollar el pensamiento; queda abierta la matriz planteada a la generación de situaciones diversas. Si bien, fueron atendidos los requerimientos de los niveles de Preescolar a Primaria, también ha sido considerado el marco de acción general hasta Secundaria para invitar a tomar conciencia de la importancia de llegar a los niveles más complejos gracias a una mediación desde temprana edad. Fácilmente puede reconocerse cuándo una situación de aprendizaje o un proceso cognitivo no forma parte de los primeros niveles educativos; no obstante, queda claro que los límites los pondrá el tiempo, la forma de mediación y el modo como el docente y el estudiante vayan superando cada reto formativo.

\section{Referencias}

Berasluce, R. (Sin fecha). Las escuelas municipales de Reggio Emilia como modelo de calidad en la etapa de educación infantil. Alicante: Editorial Club Universitario. https://books.google.com.co/books?id=9Hs0DwAAQBAJ\&p rintsec $=$ frontcover $\& \mathrm{dq}=$ Reggio + Emilia $\& \mathrm{hl}=\mathrm{es}-$ 419\&sa $=$ X\&ved $=2$ ahUKEwipwun4krnqAhXMct8KHVfoBR 8Q6AEwAnoECAMQAg\#v=onepage \&q=Reggio\%20Emilia $\& \mathrm{f}=$ false

Castro, A., \& Herrera, J. (2012). Efecto de una estrategia pedagógica basada en el uso de la modificabilidad estructural cognitiva en los niveles de ansiedad que interfieren en la producción oral en inglés de los estudiantes del ciclo II. Bogotá: Universidad Libre. Recuperado de: https://repository.unilibre.edu.co/bitstream/handle/10901/812 9/Proyecto\%20de\%20grado.pdf?sequence=1\&isAllowed=y

Cedillo, I. (2010). El aprendizaje mediado y las operaciones mentales de comparación y clasificación. Universidad de Cuenca. Recuperado http://dspace.ucuenca.edu.ec/handle/123456789/3296

Comenio, J. A. (1986). Didáctica Magna. Akal. Recuperado de: https://books.google.com.co/books?id=dx5K1Db2w2QC\&pg $=\mathrm{PA} 3 \&$ source $=\mathrm{gbs} \_$selected_pages $\& \mathrm{cad}=3 \# \mathrm{v}=$ onepage $\& \mathrm{q} \& \mathrm{f}$ $=$ false

Dijk, T. A. van. (1980). Texto y contexto. Cátedra.

Dijk, T. A. Van. (2006). De la Gramática del Texto al Análisis Crítico del Discurso. Una breve autobiografía académica. Recuperado de: http://www.discourses.org

Feuerstein, R. (1993). Modificabilidad Cognitiva y Programa de Enriquecimiento Instrumental. Manual para el alumno y el docente. Instituto Superior Pío X.

Flórez, R. (2013). Estrategias de enseñanza y pedagogía. Actual $\begin{array}{llll}\text { Pedagogía, 61, } & \text { 13-26. }\end{array}$ https://www.researchgate.net/publication/302138425_Estrate gias_de_ensenanza_y_pedagogia 
Guillen, G. (2020). La pedagogía de la imagen como forma de promover el aprendizaje significativo dentro del aula. Revista Tecnológica-Educativa Docentes 2.0, 9(1), 96-108. https://doi.org/10.37843/rted.v9i1.90

Gutiérrez-Cortés, F., Islas-Carmona, O. \& Arribas-Urrutia, A. (2019). Las nuevas leyes de los nuevos medios y la reconfiguración del entorno. Palabra Clave, 22(2), e2229. DOI: 10.5294/pacla.2019.22.2.9

Halliday, M. A. K. (2013). El lenguaje como semiótica social. Fondo de Cultura Económica.

Herrero, J. \& Martínez, J. M. (2018). Intervención mediada, representación subjetiva y variables de aprendizaje en educación primaria. Madrid, España: Centro Superior de Estudios Universitarios Recuperado de:

https://dialnet.unirioja.es/servlet/articulo?codigo=6299072

Iafrancesco, M. (2013). Aprendizajes autónomo y significativo. Desarrollo del potencial de aprendizaje y de las múltiples inteligencias. Capacitación en Universidad de Pamplona. P.P.

López, A., Vanegas, D. \& López, M. (2007). Una competencia Textolingüística en permanente desarrollo. El Guiniguada. 15 a $16,31-42$.

López, A., \& Vanegas, D. (2005). El conocimiento del texto lingüístico y su trascendencia en la Didáctica de la Lengua y la Literatura. Bordón. 57 (3), 397-405.

Martínez, M. (2002). Hermenéutica y análisis del discurso como método de investigación social. Paradigma, 23, 1-13.

MEN, (Sin fecha). Educación virtual o educación en línea Recuperado de: https://www.mineducacion.gov.co/1759/w3-article196492.html?_noredirect=1

Morin, E. (1994). Introducción al pensamiento complejo. Gedisa.

OCDE. (2019). PISA Resultados Clave. Recuperado de: https://www.oecd.org/pisa/pisa-2019-results-in-focusESP.pdf

Piaget, J. (1976). Teoría psicogenética. Springer-Verlag.

Rincón, G. (2004). ¿Cómo se está enseñando a comprender textos escritos en la educación primaria? Revista Internacional Magisterio, 7.

Solé, I. (1992). Estrategias de lectura. Graó.

Stenhouse, L. (1998). La investigación como base para la enseñanza. Morata.

Vanegas, D., Celis, R. A., \& Becerra, J. S. (2016). Modelo interdisciplinar de intervención pedagógico-didáctica propulsor de un proceso de enseñanza-aprendizaje de calidad. Revista Universidad y Sociedad, ISSN: 2218-3620, vol. 8 (1), 151-158. Recuperado de: http://scielo.sld.cu/pdf/rus/v8n1/rus21116.pdf

Vanegas, D., Ramón, A.A. \& Lizarazo, A. K. (2017). Comunidad y cultura ambiental. Revista Agua, Aire y Suelo, 8(1), 36-43.
Vanegas, D. \& Ramón, A.A. (2019). Categorías culturales en la instrumentalización del proceso lector y escritor. Revista Enunciación, ISSN: 0122-6339 (I) y 2248-6798 (E), 24 (2), p. 267-275. DOI: http://doi.org/10.14483/22486798.14137

Zeballos, M. (2020). La evaluación de los aprendizajes mediadas por las TAC. Revista Tecnológica-Educativa Docentes 2.0, 9(1), 83-95. https://doi.org/10.37843/rted.v9i1.98

Zubiría, J. (2014). El desarrollo del pensamiento: prioridad de la educación actual. Recuperado de: http://santillanaplus.com.co/pdf/estrategias-para-desarrollarlos-procesos-de-pensamiento.pdf

Zubiría, M. \& Zubiría, J. (1998). Biografía del pensamiento. Magisterio. 